\title{
Challenges on the Development of Cooperatives: The Case of Bench Maji Zone, SNNP Regional State
}

\section{Yidenek Woldesenbet}

Lecture(MBA), Mizan Tepi University, College of Business and Economics, Department of Cooperative, Ethiopia. yidenek2015@gmail.com

Abstract: This survey study aimed identifying the challenge on the development of Cooperative organizations in selected three woreda in Bench Maji zone. Responses were elicited from three hundred thirty five (335) respondents. Data were analyzed using descriptive and multi-linear regression analyses. Finally, the study has suggested cooperative promoter, government, and prospective members should prioritize those factors that have greater impact on their success than do others i.e., financial condition and their politico-legal status. The future study needs to provide longitudinal data to examine continuity of response and to observe development that occur over time and also add other developmental factors of cooperative organization (such as market access and infrastructure).

Keywords: Development of cooperative organization, management factor, structural factor, awareness factor, financial factor, politico-legal factor, entrepreneurial factor.

\section{INTRODUCTION}

When we consider human beings history, greatest socio-economic achievements have merely become possible through community participation and group collaborative work starting from the hunting and gathering way of life. In cooperatives, the members join together with a view to enjoy economic advantages by securing the goods and services they need to exist, to carry out their occupation or to run their business. The international representative body for cooperatives, the International Co-operative Alliance, defines a co-operative as: An autonomous association of persons united voluntarily to meet their common economic, social and cultural needs and aspirations, through a jointly owned and democratically controlled enterprise (ICA, 1995).

Even though, it is generally believed that successfully managed cooperatives have great potential in development; a mixture of definitions has been used, in order to determine the development of cooperatives enterprise. For instance, Curl, (2010) defines development in terms of business growth, profitability, and members' satisfaction. Tulus, October, (2004) studies co-operative success in Asia and defines development as attaining a free market paradigm.

With respect to the challenges to the development of cooperative organization, the findings in Mellor, (2009) indicates that lack of members' knowledge, lack of commitment and customer loyalty is the challenging factor for cooperative organization development.

In addition awareness factor, Birchall, (2003) considering the structural challenges to the development of cooperative organization. (Cornforth, Hall, \& Keynes, 1995) has also indicate the striking features of structures and procedures both from the point of view of efficiency and how well they meet cooperative principles, and to make changes which achieve a workable balance between different objectives. Also (Nilsson \& Ohlsson, 2007) shows, organizational structure factor for the development of market in the cooperatives will be impotant for the development of cooperative organization development. 
(Sevarlic, Raicevic, \& Glomazic, 2012) Indicate cooperatives capital as social funds for both their members and non-members which is maintained if the development of cooperative organization will be successful. Hussain, (2014)Indicate people commited to engage in cooperative activities but due to lack of capital they cannot do so, these affects the activities of Cooperative organizations especially in rural areas and it hampers economic growth.

The other important factor challenges to the development of cooperative organization is management factor. Hariyoga \& Sexton, (2009 )findings on management factor shows a number of poor business decisions that led to significant financial stress and the eventual dissolution of the firm is due to lack of available skill of the management. (Gray \& Kraenzle, 2002) identified problems on cooperative management that result in low commodity prices, the agricultural economy,operational issues, and increasing costs.

Spielman \& Bernard, (2003) indicates the government/ politico legal factor with respect to their relationship among cooperatives affects their development. (Stearns, Cobia, \& Warman, 1997) Indicate the government factor on cooperative elevator structure and operations during the late 1980s and early 1990s and shows the over control and regulation by the government led to failure of the cooperative organization.

However, currently with varying degrees of organizational development, cooperatives are longstanding and widespread throughout the country (Spielman \& Bernard, 2003; Getnet \& Tsegaye, 2012; Bezabih, 2009) indicates Ethiopian government enact cooperatives proclamations, and formulated a five year cooperative development programme and shows its implication as the realization of federal and regional governments contributed for the development of cooperatives to economic and social development, food security and poverty reduction in Ethiopia. However, Emana, (2009) adds, at the district level where most decision making on capacity building programmes, budgeting and resources allocation takes place; lack of awareness about the role of cooperatives in economic and social development, and lack of awareness regarding cooperative law has made it difficult for integrated promotion and development of cooperative organization.

Having the above issues in mind and important role cooperatives can play in the development of the country through further promotion, deepening and supporting of cooperatives is important Getnet \& Tsegaye, (2012). As a result studying on the district level challenges to the development of cooperative organization for which Bench maji zone among them would be selected.

\section{REVIEW OF LITERATURE}

The theoretical and empirical analysis found various factors as vital in development of cooperative organization. A number of studies have been carried out with the objective of establishing the relationship between various factors and its influence on the development of cooperative organization in different parts of the world. The researchers found that the impact of different factors like, management, structural, awareness, financial, politicolegal and entrepreneurial factors as significant factors on the development of cooperative organization. But no studies use entrepreneurial factor as additional variable to this five other variables. As the best knowledge of the researcher, no other research has used entrepreneurial factor as independent variable specifically in Ethiopia and this paper try to see the six factors and the its relationship with development of cooperative organization in Bench maji case.

\section{CONCEPTUAL FRAMEWORK}

For the purpose of this study, "development of cooperative organization", as the main dependent variable, is defined as the function of maximizing different developmental goals; i.e. "service offerings", and. "members` satisfaction". This definition of cooperative organization development was partially adopted, from (Bruynis et al., 2007; John W, 2009 and Esman \& Uphoff, 2008). And it evaluates the degree of Cooperatives development in terms of service offerngs to members in order to enhance member satisfaction. From the review of a broad range 
of literature, the researcher proposes the challenges to the development of cooperatives organization would in six factors: It can be argued that the challenges to the development of cooperative organizations are: Structural factor; politico-legal factor, financial factor, awareness factor, management factor and entrepreneurial factor. Moreover the following figure illustrates how these attributes would be designed as factors to the development of cooperative organization.

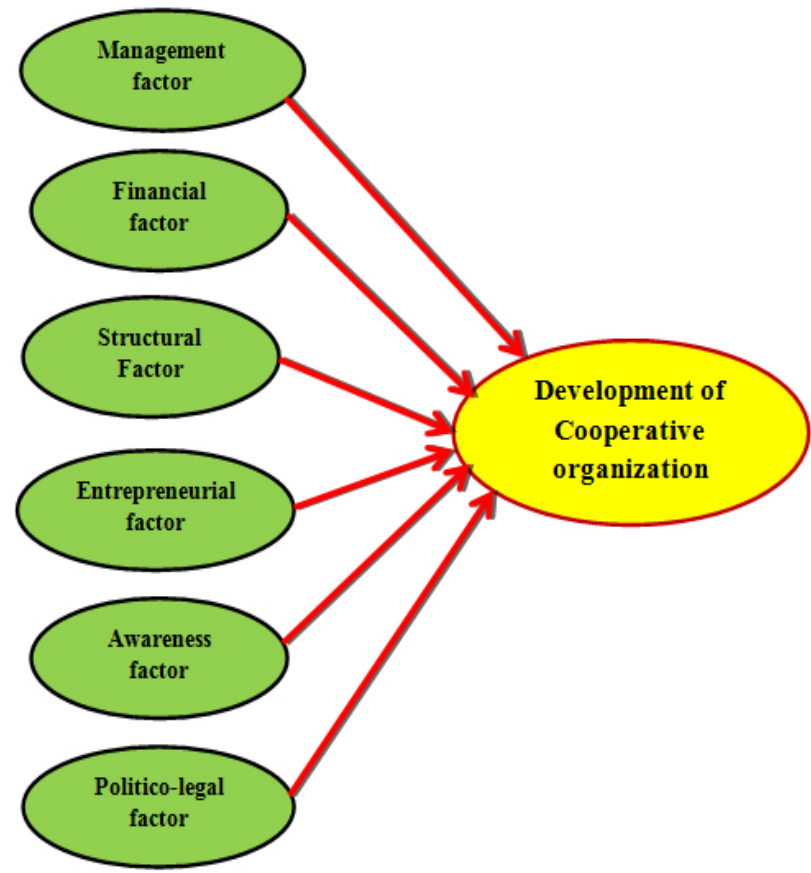

Fig. Conceptual frame work

Sources: Researcher own design based on literature

\section{NEED/IMPORTANCE OF THE STUDY}

The central purpose of this research study is to find out and examine Impact of factors on development of cooperative organization in Ethiopian, a case of Bench maji zone, SNNP Regional state and to examine the developmental factors/challenges have significantly affect the development of cooperative organization in Ethiopia. In turn, the findings of the research add to the existing knowledge. Specifically, this study is significant in the sense that:

$\checkmark$ Create meaningful awareness among the concerned body primary cooperative organization managers, DA, agricultural office workers, heatth extension workers, teachers, and FTC about the developmental factors that affect the development of cooperative organization for optimal organizational development.

$\checkmark$ The study findings help scholars to seek more knowledge about the development of organization in many other service giving institutions in order to shot light on developmental factor for organizational development.

$\checkmark \quad$ The findings also helpful in building on the already existing literature about developmental factor and organizational development of cooperative organization.

$\checkmark \quad$ The policy makers and government find the study findings vital especially in building and widening on the existing information on the developmental factors and development of cooperative organization.

$\checkmark$ Cooperative institutions find the research findings useful in providing an insight in to the sound organizational development practices. 


\section{Statement of Problem}

Starting and operating cooperatives includes a possibility of development as well as failure. Because of many factors either from the mistake done by the cooperatives or simple management mistake the cooperatives led to failure. (Mohammed \& Lee, 2015)Study on Ethiopian cooperative sector on SNNPR and indicate development stories of some or few cooperatives, and found major challenge of cooperatives organization development as due to past attitude (ideology), lack of committed leadership, lack of good governance (management), lack of working capital, attitude and practice of corruption, lack of knowledge and skill, lack in provision and utilization of improved technology, weak vertical and horizontal linkage within and among cooperatives, lack and inappropriate support from government and other stakeholders. In addition Bezabih,(2009) studied in Ethiopia indicate the major challenges on the development of cooperative organization on lack of awarness, failure in structure of the cooperatives, capital shortage and management problems.

Gaikar, (2015) An empirical study of co-operatives in India: with reference to the five year plans on the world famous co-operative and found five major challenges to the development of cooperative organization as structural factor, lack of capital, lack of awareness, poor management, and over control and regulation of the government is identified as the major problem.

Although a number of studies have examined various key issues contributing to development of cooperative organization, recent studies has pointed out that there is variety in the literature with regard to development of cooperative organization factors (Dube, (2015); Tchami, (2007); Maghsoudi \& Davodi, (2011); Panagiota \& Nastis, (2011)). Furthermore with diversity in method as well as subject matter, understandably from country to country (Kangaraj, 2012), a growing body of literature seeks further studies on factors that contributed to the success of cooperatives. Therefore, this highlights the need for further research in this area.

Moreover further analysis on the challenges toward the development of cooperative organization is essential. Limo K \& Popoi, 2011; Maghsoudi \& Davodi, 2011 indicates enterpreneurial factor as additional challenge towards the development of cooperative organization in Iran. As pointed out in Donnell, Macknigh, \& Donnelly, (2012) In scotland found entrepreneurial factors as significantly affecting the development of cooperative organization. The current research was included new variable as developmental factor, which has significant impact on the development of cooperative organization and gives policy option for the development of cooperative organization in Ethiopia that is not yet included by other researcher in Ethiopian previous study. Moreover, the current study was examine whether entrepreneurial factor has influenced the development of cooperative organization in Ethiopia; a case of Bench maji zone, SNNPR Regional state.

From the above research gap found in the empirical studies, this study attempt to fill the gap by investigating the impact of entrepreneurial factor on the development of cooperative organization in Ethiopia.

\section{OBJECTIVE OF THE STUDY}

\section{General Objective}

The general objective of the study is to analyze the challenges to the development of cooperative organization in Bench maji zone.

\section{Specific Objectives}

In an attempt to achieve the general objective of the research, it also addressed the following specific objectives are:

$\square$ To examine the relationship between management factors and development of cooperative organization in Bench maji case. 
$\rightarrow$ To examine the relationship between structural factors and development of cooperative organization in Bench maji case.

To examine the relationship between awareness factors and development of cooperative organization in Bench maji case.

\section{HYPOTHESIS}

With the help of sufficient and appropriate empirical data, various factors that affect the development of cooperative organization. Dube, (2015) indicate modern economic and social structures may have weakened co-operative social fabric but it is an important foundation upon which the concept and philosophy of modern co-operatives as economic enterprises can be successfully built and sustained. From all some researchers namely, Gaikar, (2015); Develtere et al. (2008); Chambo, (2009); Dias, (2012); Kanagaraj, (2012); and Emana, (2009) indicate there are various factors affecting development of cooperative organizations.

From the above empirical study, the researcher tries to develop testable hypotheses to examine the impact of factors on the development of cooperative organization in Ethiopia: a case of Bench Maji zone; SNNPRegional state. The research hypothesis was developed to estimate the sign of the relation by supporting with empirical evidence to examine the relationship between factors affecting the development of cooperative organization in terms of managerial factor(Mgrf), structural factor(Strf), awareness factor(Awf), financial factor(Finf), politicolegal factor(Polf) and entrepreneurial factor(Enf).

\section{Managerial Factor (MGRF)}

Theoretically, good management increases the effectiveness and performance of cooperative organization, which in turn increase the development of cooperative organization. Dube, (2015) indicate the positive and significant relation of management and development of selected 390 village primary milk cooperative societies, by a newly appointed group of professional managers through training and technical help. In addition Curl, (2010); Wanyama, (2008); and Dogarawa, 2005) also show positive and significant relation between management and development of cooperative organization through their interpersonal skills of managers, good understanding the concept of cooperative, good educational level, and good experience in cooperative.

Over all, most of the empirical studies indicate positive relationship between management and development of cooperative organization. Therefore, this study expected that management factor has positive and significant impact on development of cooperative organization in Ethiopia.

\section{Hypothesis 1: Mgrf has significant positive impact on development of cooperative organization}

\section{Structural Factor (STRF)}

Most of the empirical literature made around the world put the result that structural factor in terms member homogeneity, members' cooperation, practice of sharing experiences of other developed cooperatives, good relationship with other cooperatives, availability of well-structured facilities, and large number of workers has positive impact on development of cooperative organization.

A study by (Hariyoga \& Sexton, (2009) ; Fulton \& Hueth, (2009); Cornforth et al. (1995) and Nilsson \& Ohlsson, (2007) conclude that structural factor has positive and statistically significant on the development of cooperative organization.

Over all, most of the empirical studies indicate positive relationship between structural factor and development of cooperative organization. Therefore, this study expected that structural factor has positive and significant impact on development of cooperative organization in Ethiopia.

\section{Hypothesis 2: Strf has significant positive impact on development of cooperative organization}




\section{Awareness Factor (AWF)}

Awareness in cooperative context means incorporating effective member-owner awareness in order to help develop the capacity of the management and members to listen well and respond appropriately to the genuine concerns of the cooperative organization in terms of good communication medium, members access to timely, worthwhile information and provide regular feedback to members to allow them to share in collective successes as highly important in terms of its influence on the development of society's, awareness on member owner responsibility and benefits, awareness of related cooperatives news and market trends, accuracy of messages cooperatives communicate to members. According to Mellor, (2009); Emana, (2009); Bond et al. (2009); Fulton \& Hueth, (2009) conclude that awareness factor has positive and statistically significant on the development of cooperative organization.

Over all, most of the empirical studies indicate positive relationship between awareness factor and development of cooperative organization. Therefore, this study expected that awareness factor has positive and significant impact on development of cooperative organization in Ethiopia.

\section{Hypothesis 3: Awf has significant positive impact on development of cooperative organization}

\section{Financial Factor (FINF)}

In theory finance of cooperative means one of the key important influential term if cooperatives are established, grow and flourish, which critically focus on the development of cooperative organization.

Most of the empirical literature made around the world put the result that financial factor in terms share capital contribution, loan application by banks and other lending institution, cash management skill, interest charged by banks and other lending institutions and high collateral requirements for banks and other lending institution.

A study by ICA, (2013); Gray \& Kraenzle, (2002); Dogarawa (2005) conclude that financial factor has positive and statistically significant on the development of cooperative organization.

Over all, most of the empirical studies indicate positive relationship between financial factor and development of cooperative organization. Therefore, this study expected that financial factor has positive and significant impact on development of cooperative organization in Ethiopia.

\section{Hypothesis 4: Finf has significant positive impact on development of cooperative organization}

\section{Politico-Legal Factor (POLF)}

Many empirical study analysis politico-legal influences on development of cooperative organization in terms of Lack of accessible information on government regulation that are relevant to cooperatives, political intervention, bureaucracy in cooperative registration and licensing, tax levied on cooperative business and government support.

According to Gorz, (2007); Gray \& Kraenzle, (2002) and Hussain, (2014) the empirical results of their study show that the politico-legal factor is positive and statistically significant with the development of cooperative organization. In Ethiopia, research by Veerakumaran, (2007); Kanagaraj, (2012); Emana, (2009); Getnet \& Anullo, ( 2012) indicate politico-legal factor has positive and statisticaly significant with the development of cooperative organization.

Therefore, most of the empirical studies indicate positive relationship between politico-legal factor and development of cooperative organization. Therefore, this study expected that politico-legal factor has positive and significant impact on development of cooperative organization in Ethiopia.

Hypothesis 5: Polf has significant positive impact on development of cooperative organization 


\section{Entrepreneurial Factor (ENF)}

Many empirical study analysis Entrepreneurial influences on development of cooperative organization in terms of entrepreneurship training, tolerance to work hard, motivation and drive, absence of initiative to assess one's strengths and weakness, persistence and courage to take responsibility for one's failure and lack of information to exploit business opportunities.

According to Donnell et al. (2012); Maghsoudi \& Davodi, (2011) the empirical results of their study show that the entrepreneurial factor is positive and statistically significant with the development of cooperative organization.

Therefore, most of the empirical studies indicate positive relationship between entrepreneurial factor and development of cooperative organization. Therefore, this study expected that entrepreneurial factor has positive and significant impact on development of cooperative organization in Ethiopia.

\section{Hypothesis 6: Enf has significant positive impact on development of cooperative organization}

\section{RESEARCH METHODOLOGY}

\section{Sampling Design}

Dattalo, (2008) indicate multiple approaches to calculating appropriate effect-size values and corresponding sample sizes should be used and he sggests as one strategy might be to begin with a sample size and, through resampling, explore the consequences of incremental changes in sample size on power. Therefore for the sample house hold, have to be determined as, to be more scientific, Yamane (1967), the sample size is based on the following proposed simplified formula.

$\boldsymbol{n}=\frac{N}{1+N(e)^{2}}$, in which is the level of precision i.e., $e=0.05$ (level of precision assumed for the purpose of determining sample size).

$$
\text { Where: } \mathbf{n}=\frac{N}{1+N(e) 2}=\frac{4635}{1+4635(0.05) 2}=\frac{4635}{12.6} \approx \underline{\underline{368}}
$$

$\mathrm{n}$ = number of sample size, $\mathrm{N}=$ Total number of study population, $\mathrm{e}=$ level of confidence is $95 \%$ for this study.

\section{Data Collection Tools and Techniques}

\section{Questionnaire}

The literature in the study was used as a guideline for the development of the questions in the questionnaire. Some questions in the questionnaire were partially adopted from other sources Azadi, et al. (2010) were employed to collect quantitative and qualitative data.

The validity of the questionnaire was approved through face validity. The reliability of the indices used was tested both in the pilot study and after the completion of the study. To assess reliability and internal consistency of the variables, Cronbach's "alpha" was calculated. A benchmark alpha of .70 was set as an acceptable measure of reliability (Cronbach, 1951). Based on this an internal consistency reliability the Cronbach's alpha coefficient for the instrument was found as 0.837 which is highly reliable.

\section{Interview}

The interview method of collecting data involves presentation of oral-verbal stimuli and reply in terms of oralverbal responses (R. Kothari, 2004). Semi-structured interview will be used to gather in-depth qualitative data from officers of zone and woreda promotion officers, and also from the primary and secondary cooperative management and officers. Using semi-structured interview is important, because it provide opportunity to observe non-verbal behavior of respondents; gives opportunities for clearing up misunderstandings, as well as it can be adjusted to meet many diverse situations (Creswell, 2009) 


\section{Data Processing AND AnAlysis}

\section{Data Processing}

Data processing has two phases namely: data clean-up and data reduction. During data clean-up the collected raw data was edited to detect anomalies, errors and omissions in responses and checking that the questions are answered accurately and uniformly.

\section{Data Analysis}

After the data processing have been done the next tasks was analyzing the processed data. This is the further transformation of the processed data to look for patterns and relationship between and/or among data groups by using descriptive and multiple regression analysis. The Statistical Package for Social Science (SPSS) version 20 was used to analyze the data obtained from primary sources.

Interviews and qualitative nature questions in the questionnaire are considered as qualitative data, which together will be processed in to themes and arranged to relatedness. Finally, considering all the variable, findings, conclusions, and some possible recommendations will be drawn.

\section{Model Specification and Description of Study Variables}

Then multi-linear regression analysis shows the association between two or more variables and how several independent variables might explain the variance in a dependent variable through Pearson product moment correlation coefficient. Pearson product moment correlation Coefficient is a widely used statistical method for obtaining an index of the relationships between two variables when the relationships between the variables is linear and when the two variables correlation are continuous. To ascertain whether a statistically significant relationship exists between management factors, awareness factors, structural factors, financial factors, politico-legal factors and entrepreneurial factors with the development of cooperative organization, the Product Moment Correlation Coefficient was used.

According to Duncan and Dennis (2004:38-41), correlation coefficient can range from -1 to +1 . The value of -1 represents a perfect negative correlation while a value of +1 represents a perfect positive correlation. A value of 0 correlations represents no relationship. The results of correlation coefficient may be interpreted as follows.

Regress development status of cooperative organization on Selected Variables

$Y_{1}=\beta_{0}+\beta_{1} X_{1}+\beta_{2} X_{2}+\beta_{3} X_{3}+\beta_{4} X_{4}+\beta_{5} X_{5}+\beta_{6} X_{6}$

Where: $\mathrm{Y}$ is the response or dependent variable- Development status of COOP's organization;

$X_{1}=$ management factors, $X_{2}=$ awareness factors, $X_{3}=$ structural factors, $X_{4}=$ financial factors, $X_{5}=$ politico-legal factors and $\mathrm{X}_{6}=$ entrepreneurial factors

$\beta_{0}$ is the intercept term constant which would be equal to the mean if all slope coefficients are 0 .

$\beta_{1}, \beta_{2}, \beta_{3}, \beta_{4}, \beta_{5}, \beta_{6}$ are the coefficients associated with each independent variable which measures the change in the mean value of $Y$, per unit change in their respective independent variables.

\section{RESULT AND DISCUSSION}

\section{Regressions Analysis}

The basic assumptions of multiple regressions were checked before going to analysis and all assumptions were meet successfully. The decisions rule for Durbin-Watson statistics is that a p-value approaching two indicates that there is no auto-correlation problem. As shown in the DW table below there is no problem of auto-correlation. 
Challenges on the Development of Cooperatives: The Case of Bench Maji Zone, SNNP Regional State

Table 4.10. DW statistics

\section{Durbin-Watson}

1.84

Source: Field survey, 2016

The other assumption test by Guajarati (2004) is one of the assumptions of the classical linear regression model is that there is no multicollinearity among the explanatory variables, the X's. According to Kennedy (2008) multicollinearity problem exists when the correlation coefficient among the variables are greater than 0.70 .

\section{Correlation}

\begin{tabular}{|c|c|c|c|c|c|c|c|}
\hline & Docorg & Mgrf & Strf & Awrf & Finf & Polf & Enf \\
\hline Docorg & 1 & & & & & & \\
\hline Mgrf & $.693^{* *}$ & 1 & & & & & \\
\hline Strf & $.609^{* *}$ & $.410^{* *}$ & 1 & & & & \\
\hline Awrf & $.627^{* *}$ & $.388^{* *}$ & $.306^{* *}$ & 1 & & & \\
\hline Finf & $.896^{* *}$ & $.623^{* *}$ & $.531^{* *}$ & $.566^{* *}$ & 1 & & \\
\hline Polf & $.708^{* *}$ & $.494^{* *}$ & $.413^{* *}$ & $.290^{* *}$ & $.632^{* *}$ & 1 & \\
\hline Enf & $.247^{* *}$ & $.206^{* *}$ & $.144^{* *}$ & $.226^{* *}$ & $.201^{* *}$ & $.033^{*}$ & 1 \\
\hline
\end{tabular}

**. Correlation is significant at the 0.01 level (2-tailed).

*. Correlation is significant at the 0.05 level (1-tailed).

Source: Field survey, 2016

Multiple linear regressions method was used to determine how development of cooperative organizations is affected by six factors. The regression analysis is presented as follows.

\section{Model Summary}

\begin{tabular}{|c|c|c|c|c|c|}
\hline \multicolumn{5}{|c|}{ Model Summary } \\
\hline Model & $\mathrm{R}$ & R Square & Adjusted R Square & Std. Error of the Estimate & Durbin-Watson \\
\hline 1 & $.948^{\mathrm{a}}$ & .899 & .897 & .328 & 1.838 \\
\hline
\end{tabular}

Source: Field survey, 2016

a. Predictors: (Constant), entrepreneurial factor, Politico-legal factor, awareness factor, structural factor, managerial factor, Financial factor

b. Dependent Variable: development of cooperative organization

Analysis of table above shows the correlation between the observed value of development of cooperative organization and the optimal linear combination and the independent variable (managerial, structural, awareness, financial, politico-legal and entrepreneurial factor) is 0.948 , R square 0.899 and adjusted R square 0.897 , and it may be realized that $89.9 \%$ explained by the explanatory variables and the remaining $10.1 \%$ of the variable is explained by other variable not included in the study.

Table 4.13. ANOVA

\begin{tabular}{|c|c|c|c|c|c|c|}
\hline \multicolumn{9}{|c|}{ ANOVA $^{\mathrm{a}}$} \\
\hline \multirow{3}{*}{1} & Model & Sum of Squares & Df & Mean Square & F & Sig. \\
\hline \multirow{3}{*}{1} & Regression & 314.237 & 6 & 52.373 & 486.188 & $.000^{\mathrm{b}}$ \\
\cline { 2 - 8 } & Residual & 35.333 & 328 & .108 & & \\
\cline { 2 - 8 } & Total & 349.570 & 334 & & & \\
\hline
\end{tabular}

Source: Field survey, 2016

American Research Journal of Business and Management 
Challenges on the Development of Cooperatives: The Case of Bench Maji Zone, SNNP Regional State

a. Dependent Variable: development of cooperative organization

b. Predictors: (Constant), entrepreneurial factor, Politico-legal factor, awareness factor, structural factor, managerial factor, Financial factor

\begin{tabular}{|c|c|c|c|c|c|c|c|c|c|c|c|c|c|}
\hline \multicolumn{14}{|c|}{ Coefficients $^{a}$} \\
\hline & \multirow[t]{2}{*}{ Model } & \multicolumn{2}{|c|}{$\begin{array}{c}\text { Unstandardized } \\
\text { Coefficients }\end{array}$} & \multirow{2}{*}{$\begin{array}{c}\text { Standardized } \\
\text { Coefficients }\end{array}$} & \multirow[t]{2}{*}{$\mathrm{T}$} & \multirow[t]{2}{*}{ Sig. } & \multicolumn{2}{|c|}{$\begin{array}{c}99.0 \% \text { Confidence } \\
\text { Interval for B }\end{array}$} & \multicolumn{3}{|c|}{ Correlations } & \multicolumn{2}{|c|}{$\begin{array}{c}\text { Collinearity } \\
\text { Statistics }\end{array}$} \\
\hline & & B & $\begin{array}{l}\text { Std. } \\
\text { Error }\end{array}$ & & & & $\begin{array}{l}\text { Lower } \\
\text { Bound }\end{array}$ & $\begin{array}{l}\text { Upper } \\
\text { Bound }\end{array}$ & $\begin{array}{l}\text { Zero- } \\
\text { order }\end{array}$ & Partial & Part & Tolerance & VIF \\
\hline \multirow{7}{*}{1} & (Constant) & .895 & .091 & & 9.871 & .000 & .660 & 1.130 & & & & & \\
\hline & Mgrf & .128 & .020 & .148 & 6.406 & .000 & .077 & .180 & .693 & .333 & .112 & .578 & 1.730 \\
\hline & Strf & .106 & .016 & .141 & 6.724 & .000 & .065 & .147 & .609 & .348 & .118 & .699 & 1.431 \\
\hline & Awf & .136 & .016 & .181 & 8.372 & .000 & .094 & .178 & .627 & .420 & .147 & .659 & 1.518 \\
\hline & Finf & .270 & .017 & .476 & 15.999 & .000 & .226 & .313 & .896 & .662 & .281 & .348 & 2.874 \\
\hline & Polf & .172 & .018 & .222 & 9.458 & .000 & .125 & .219 & .708 & .463 & .166 & .560 & 1.785 \\
\hline & Enf & .040 & .014 & .052 & 2.827 & .005 & .003 & .076 & .247 & .154 & .050 & .914 & 1.094 \\
\hline
\end{tabular}

Source: Field survey, 2016

a. Dependent Variable: development of cooperative organization

The coefficient analysis result shows that the predictor variables managerial $(\mathrm{P}=0.000)$, structural $(\mathrm{P}=0.000)$, awareness $(\mathrm{P}=0.000)$, financial $(\mathrm{P}=0.000)$, politico-legal $(\mathrm{P}=0.000)$ and entrepreneurial factor $(\mathrm{P}=0.005)$ are statistically significant.

In conclusion, managerial, structural, awareness, financial, politico-legal and entrepreneurial factor are the factors that determine the level of development in cooperative organizations.

The model is:

$Y=\beta_{0}+\beta_{1}$ Mgrf $+\beta_{2} \operatorname{Strf}+\beta_{3}$ Awf $+\beta_{4}$ Finf $+\beta_{5}$ Polf $+\beta_{6}$ Enf

Therefore, $\beta_{0}=.895, \beta_{1}=0.148, \beta_{2}=0.141, \beta_{3}=0.181, \beta_{4}=0.476, \beta_{5}=0.222, \beta_{6}=0.052$

$Y=0.895+0.148($ Mgrf $)+0.141($ Strf $)+0.181($ Awf $)+0.476$ (Finf $)+0.222$ (Polf) $+0.052($ Enf $)$

This multiple regression equation tells us following results.

As coefficients table 4.13 of the regression presents, all of six independent variables (management factor, structural factor, awareness factor, financial factor and politico-legal factor and entrepreneurial factor) found significant predictors of the dependent variable (development of cooperative organizations). Furthermore as the standardized beta value shows Financial factor and politico-legal factor found as the strongest predictor of development of cooperative organization with the $\beta$ value of .476 and .222 respectively. This result is consistent with the findings of (Veerakumaran, 2007), Kanagaraj, (2012); Emana, (2009); Hussain, (2014); Gray \& Kraenzle, (2002); Goddard, et.al (2009)and; Dube, (2015). Therefore; we need to work more on improve financial condition and politico-legal ground in order to make the development of cooperative organization. In other word, decline in finance and politico-legal instability are factors behind the cooperative failure.

The other variable which are significant for the development of cooperative organizations are managerial factor with the beta value of .148 and awareness with beta value of .181. This result is supported by the findings of 
Kanagaraj, (2012); Dube, (2015); Bond, et.al (2009); Purvis (2007); Azadi et al. (2010); Scribner (2007); Emana, (2009); Kanagaraj, 2012; and Hussain, 2014;). Therefore, specific factors related to managerial and awareness factors should be met satisfactorily in order to have a development of cooperative organization. Furthermore, factors such as good interpersonal skills of managers, good understanding the concept of cooperative, good educational level, good experience of management in cooperative of managerial factor and good communication medium, members access to timely and worthwhile information, regular feedback to members to allow them to share in collective successes awareness on member owner responsibility and benefits, awareness of related cooperatives news and market trends and accuracy of messages cooperatives communicate to members of awareness factors of awareness factor which need emphasis in order to reduce cooperative business failure

Finally, factors which are significant for the development of cooperative organizations are structural factor with the beta value of .141 and entrepreneurial factor with beta value of .052 . This result is supported by the findings of Kanagaraj, (2012); Dube, (2015); Tchami, (2007); Maghsoudi \& Davodi, (2011); Panagiota \& Nastis, (2011); Hussain, 2014;). Therefore, specific factors related to structural and entrepreneurial factors should be met satisfactorily in order to have a development of cooperative organization. Furthermore, factors such as member homogeneity, members' cooperation and practice sharing experiences of other developed cooperatives, good relationship with other cooperatives, availability of well-structured facilities and large number of workers of structural factors and entrepreneurship training, tolerance to work hard, motivation and drive and absence of initiative to assess one's strengths and weakness has an entrepreneurial factor are important for the development of cooperative organization. In light of these findings, it is interesting to note that, if these factors are arranged well we can substantially reduce the failure rate of cooperative business and achieve higher success rate of cooperative organization.

\section{RECOMMENDATIONS}

In this sub section based on the empirical results of this study the researcher provides the following recommendations with regard to the developmental factors of cooperative organization. The researcher believes that giving due attention and an in-depth analysis of the following recommendations can even reduce the failure rate of cooperatives.

Since it is confirmed that the financial factor is really important contributor to cooperative organization development, the cooperative leaders, promoters and other stakeholders should encourage member share contribution for the development of cooperative organization.

Cooperatives need to find a stable ground of politico-legal condition as regulatory framework and support policies that are coherent with the co-operative form and favor its development as another factor. Therefore to support cooperative and act accordingly it must have strong legal ground.

Finally, management affects effective performance of cooperative organization and it needs a lot of expertise and understanding of the management on collective work and can better realize the key points of the cooperative development. Therefore in order to make more successful interpersonal skill of managers and its experience to cope up diverse situation have to be considered.

Finally, all cooperative concerned organization or individuals should work with members in increasing members' faith to cooperative philosophy in order to boost up the spirit cooperation and understanding involvement, mutual trust and good will by conducting different training courses and sharing best experiences and enlightening the success stories as concrete example. As overall recommendation, the study has suggested present and future cooperative promoter, government, prospective members and other stakeholders to take those identified development factors into consideration while they organize cooperative, making policies and strategies for cooperatives. In addition, since cooperative firms have very limited resources to solve their 
problems, it is critical to prioritize those items that have greater impact on their success than do others. This is expected to give cooperatives a competitive, successful and sustainable advantage of understanding and doing business in the competitive business environment.

\section{CoNCLUSIONS}

The study was conducted using six major groups of variables, namely managerial, structural, awareness, financial, politico-legal and entrepreneurial factors. The main accompanying research question posed in the study was to investigate the most influential developmental factor of cooperative organizations. The question was investigated using data collected from member of primary cooperatives functioning in Shebench woreda, Semienbench woreda and Debubbench woreda of Bench maji zone. Moreover, the major conclusions about these success factors are presented hereunder:

In comparing the mean score of the factors relating to financial and politico-legal the study found that share capital contribution, loan application by banks and other lending institution, cash management skill, accessible information on government regulation that are relevant to cooperatives, political intervention, and bureaucracy in cooperative registration and licensing are the most influential factors for the development of cooperative organization. More precisely, to be successful organizational development, the study argues that members should pay attention for their member share capital contribution in line with the legal ground.

With regard of managerial and awareness factors the study identified that although there are many managerial and awareness factors which have substantial contribution to the development of cooperative organization; interpersonal skill of managers, understanding the concept of cooperative, good communication medium, educational qualification, and member access to timely and worthwhile information are factors that affect the development of cooperative organization.

Structural and entrepreneurial factors were also identified as critical factors for development of cooperative organization. The studies concludes member homogeneity, members' cooperation and practice sharing experiences of other developed cooperatives, good relationship with other cooperatives, availability of wellstructured facilities and large number of workers, entrepreneurship training, tolerance to work hard, motivation and drive and absence of initiative to assess one's strengths and weakness factors are as the most influential items that have significantly contributed to the development of cooperative organization.

Finally, it is important to consider the results of multi-linear regression for the relationships between development of cooperative organization and its independent variables are linear and positive ranging from low to strong correlation coefficients. Besides, the result of multiple regression analysis clearly illustrates that, even if all of six independent variables i.e., managerial, structural, awareness, financial, politico-legal and entrepreneurial factor found significant predictors of the development of cooperative organization; financial, politico-legal and managerial factors are the most significant and strongest predictor of development of cooperative organization as compared to other factors in the research area.

\section{SCOPE FOR FURTHER RESEARCH}

This study has yielded considerable results and produced substantial contributions to the existing body of knowledge; however, there are also significant limitations which require further research that rigorously tests its validity and applicability in other populations to be conducted.

The limitations of the study are primarily related to the methodology, the study undertaken was cross-sectional, which various segments of a population are sampled and data are collected at a single moment in time. However, the study observes that those developmental factors in cooperatives are better understood if we collect data at different time. Therefore, the future study needs to provide longitudinal data to examine continuity of response and to observe development that occur over time and also add other developmental factors of cooperative organization (such as market access and infrastructure).

American Research Journal of Business and Management

Page 12 


\section{REFERENCES}

1. Azadi, H., Hosseininia, G., Zarafshani, K., Heydari, A., \& Witlox, F. (2010). Factors influencing the success of animal husbandry cooperatives: A case study in Southwest Iran. Journal of Agriculture and Rural Development in the Tropics and Subtropics, Vol. 111 No. 2, 89-99.

2. Balamurugan, D. S. (2013). The role of SNNPRS marketing and cooperative bureau in the expansion and development of cooperatives in SNNPR region, Ethiopia, Africa. international journal of research in commerce, it \& management, volume no. 3 , issue no. 02 , Pp(17-26.)

3. Bezabih E., (2009). Cooperatives: a path to economic and social empowerment in Ethiopia. Coop africa working paper No. 9, ILO. Dar es Salaam.

4. Birchall, J. ( 2003). Rediscovering the cooperative advantage poverty reduction through self-help, ILO, Geneva.

5. Bond, J. K. (2009). Cooperative Financial Performance and Board of Director Characteristics: A Quantitative Investigation. Journal of Cooperatives, volume -22, $\mathrm{Pp}(22-44)$.

6. Bond, J. K., Carter, C. A., \& Sexton, a. R. (2009). A Study in Cooperative Failure: Lessons from the Rice Growers Association of California. Journal of Cooperatives, 71-86.

7. Bourlakis, D. M., \& Bourlakis, D. C. (2004). Food retail logistics operations: efficient co-operatives and less efficient multiples? International Journal of Co-operative Management, volume-1(2), $\mathrm{Pp}(9-14)$

8. Chambo, S. A. (2009). Agricultural co-operatives: role in food security and rural development: Moshi University College of Co-operative and Business Studies, Tanzania.

9. Cornforth, C., Hall, W., \& Keynes, M. (1995). Report of the COPAC Open Forum: Decent Work: Can Cooperatives Make a Difference?, ILO, Geneva.

10. Crame, D., \& Howitt, D. (2004). The SAGE Dictionary of Statistics, $1^{\text {st }}$ edition. London: SAGEPublications.

11. Creswell, J. W. (2009). Research design: Qualitative, quantitative, and mixed methods approache- third edition. Los Angeles: SAGE Publications. Inc.

12. Curl, J. (2010). The Cooperative Movement in Century 21. A Journal of Radical Theory, Culture, and Action, (Volume 4), Pp(12-29).

13. Dattalo, P. (2008). Determining Sample Size: Balancing Power, Precision, andPracticality, $1^{\text {st }}$ edition. New York: Oxford University press.

14. Dejene, E. (2014). Assessment of Members Perceptions towards Factors Influencing the Success of Cooperatives, masters thesis, Mekele University, department of management.

15. Develtere, P., Pollet, I., \& Wanyama, F. (2008). Cooperating out of poverty. ILOand World Bank Institute, Geneva

16. Diarmid, M. (2006). Enabling cooperative development. United States of America: Cooperative Development Program, USAID.

17. Dias, A. (2012). The Cooperative Development and Strategy. International Journal of Accounting and Financial Reporting, volume-2(1), 191-202.

18. Dogarawa, A. B. (2005). The Role of Cooperative Societies in Economic Development, Zaria-Nigeria, Ahmadu Bello University, , Department of Public Administration.

American Research Journal of Business and Management

Page 13 
19. Donnell, D., Macknigh, E., \& Donnelly, H. (2012). Co-operative Entrepreneurship: Co-operate for growth. Scotland: University of Aberdeen.

20. Dube, ( 2015 ). Draft ethekwini co-operative development strategy, Durban, submited to business support, market and tourism unit: Ethekwini municipality.

21. FAO. (2010). Promoting employment and entrepreneurship for vulnerable youths in West Bank. F. Dalla Valle. Rome.

22. Federal negarit gazeta (1998). Cooperative societies proclamation no 147/1998. Addis Ababa, Ethiopia: Berhanena selam printing enterprise.

23. Flygare, S. (2007). Farmer Cooperation and the Politics of Agricultural Modernisation in 21st Century Studies in Economic History, Uganda.

24. Francoisheneri, J. (2002). Performance measurement and organizational effectiveness, doctoral dessertation, Laval university, School of accounting, Canada.

25. Fulton, M. E., \& Hueth, B. (2009). Cooperative Conversions, Failures and Restructurings: An Overview. Journal of Cooperatives, volume-23, $\mathrm{Pp}(\mathrm{i}-\mathrm{xi})$.

26. Gaikar, V. (2015). An empirical study of co-operatives in India: with reference to the five year plans. International Conference on Issues in Emerging Economies (ICIEE), 29-30 January. The Business \& Management Review (Volume 5 Number 4), $\mathrm{Pp}(25-29)$.

27. Garnevska, E., Liu, G., \& Shadbolt, N. M. (2011). Factors for Successful Development of Farmer cooperatives in Northwest China. International Food and Agribusiness Management Review, Volume 14, Issue 4, Pp (6984).

28. Getinet, K., \& Tsegaye, A. (2012). Agricultural cooperatives and rural livelihoods: evidence from Ethiopia. Annals of Public and Cooperative Economics Volume-83, Pp(181-198).

29. Gorz, A. ( 2007). Labour, Capital and Society. Cooperative Development and Labour Solidarity: a NeoGramscian Perspective on the Global Struggle Against Neoliberalization, p. 61.

30. Gray, T. W., \& Kraenzle, a. C. (2002). Problems and Issues Facing Farmer Cooperatives. United states. USDA.

31. Hailu, G., \& Goddard, E. (2009). Sustainable Growth and Capital Constraints: The Demutualization of Lilydale Co-operative Ltd. Journal of Cooperatives, volume-23, Pp (116-129).

32. Hariyoga, H., \& Sexton, R. J. (2009 ). The Rise and Fall of Tri Valley Growers Cooperative . Journal of Cooperatives, 87-100.

33. Hussain, M. S. (2014). The Role of Cooperative Organizations in Rural Community Development in Nigeria: Prospects and Challenges. Academic Research International, Vol. 5(3), 189-197.

34. Kanagaraj, K. (2012). A Study on Challenges and Opportunities of ConsumerCooperative Societies in Hawassa City, SNNPR, Ethiopia - An Analytical Approach. CLEAR IJRCM, Volume 2(3), Pp (1-25).

35. Katz, M. J. (2009). From Research to Manuscript; A Guide to Scientific Writing, $2^{\text {nd }}$ edition. Springer Science \& Business Media.

36. Kazakopoulos, L., Gidarakou, I., \& Theofilidou, K. ( 2003). Women's Cooperatives in Greece and the Niche Market Challenge. journal of rural cooperation, volume, 31(1): $\mathrm{Pp}(25-45)$

37. Lasley, P., Baumel, C. P., Deiter, R., \& Hipple, P. (1997). Strengthening Ethics Within Agricultural Cooperatives. RBS Research Repor.

American Research Journal of Business and Management

Page 14 
38. Limo K, S., \& Popoi, M. (2011). Effects of liberalization on dairy cooperatives in western province, Kenya. International Journal of Current Research.

39. Maghsoudi, T., \& Davodi, H. ( 2011). Entrepreneurship Development Strategies in Agriculture Cooperatives in Iran. American-Eurasian J. Agric. \& Environ. Sci., volume-10 (2): 283-289,

40. Mellor, D. J. (2009). Measurements for tracking Indicators of Cooperative success. United States: OCDC.

41. Mills, C., \& Davies, W. (2013). Blue print for a cooperative decade. Oxford:ICA.

42. Mohammed, N., \& Lee, B. W. (2015). Role of Cooperatives in Rural Development, the Case of South Nations Nationalities and People. Journal of Business and Management, Vol 3(4), Pp(102-108).

43. Mullins, L. J. (2005). Management and Organisational Behaviour. Spain: Mateu-Cromo, Artes Graficas.

44. Muthyalu, D. M. (2013 ). The Factors that Influence the Participation of Cooperative Members in the Agricultural Input and Output Marketing - A Case Study of AdwaDistrict, Ethiopia. Journal of Business Management \& Social Sciences Research, Volume 2, No.4, 121.

45. Nilsson, J., \& Ohlsson, C. (2007). The New Zealand Dairy Cooperatives' Adaptation to Changing Market Conditions. Journal of rural cooperation, volume 35(1), Pp(43-70).

46. Panagiota, S., \& Nastis, S. A. (2011). Collective entrepreneurship in agriculture and its contribution to sustainable rural development in Greece. Journal of the GeographicalInstitute, volume-61(2), Pp(109128).

47. R.Kothari, C. ((2004)). Research Methodology: Methods and Techniques, 2nd edition. New Delhi: New Age International (p) limited.

48. Satgar, V. (2007). Cooperative Development and Labour Solidarity: a Neo-Gramscian Perspective on the Global Struggle Against Neoliberalization. Johannesburg, confrence publication: COPAC.

49. Sekaran, U. (2003). Research methods for business; A Skill-Building Approach ; $4^{\text {th }}$ Edition. Carbondale: John Wiley \& Sons, Inc.

50. SevarliC, M., Raicevc, V., \& Glomazic, R. (2012). Sustainable development of the farmers' cooperative system in ap Vojvodina. Economics of Agriculture, Volume 3 (413-432).

51. Shiker, M. A. (2012). Multivariate Statistical Analysis. British Journal of Science, Vol. 6 (1), Pp(55-66).

52. Siegel, J. S. (2006). Small business and entreprenuer. eJournal USA: Economic Perspectives, volume 11(1), $\operatorname{Pp}(1-29)$.

53. Sizya, M. J. (2001). The role co-operatives play in poverty reduction in Tanzania. Moshi: United Nations Division for Social Policy and Development.

54. Somavia, J. (2000). Decent work: can cooperative makes difference? Geneva: COPAC.

55. Spielman, D. J., \& Bernard, T. (2003). Mobilizing Rural Institutions for Sustainable Livelihoods and Equitable Development: A Case Study of Farmer Cooperatives in Ethiopia: An overview. Washington, DC: World Bank.

56. Stearns, L., Cobia, D. W., \& Warman, M. (1997). Response of Cooperative Elevators to Changes in Government Policies. USDA.

57. Sumelius, J., Tenaw, S., Bee, F. K., \& Chambo, S. (2015). Agenda on cooperatives for development cooperation in Tanzania. Journal of Co-operative Organization and Management,Volume 3(2), Pp(98-100).

58. Tchami, G. (2007). Handbook on Cooperatives for use by Workers' Organizations. Geneva: ILO. 
59. Tharenou, P., Donohue, R., \& Cooper, B. (2007). Management Research Methods, $1^{\text {st }}$ edition. Cambridge: Cambridge University Press.

60. Tulus, R. (October 2004). The PRSP and Decent Work in Asia. The role of co-operatives in poverty reduction. International Journal of Co-operative Management Volume 1 (2 ), $\mathrm{Pp}(22-33)$.

61. Veerakumaran, (2007). Ethiopian Cooperative Movement-An Explorative Study. Mekelle University, Faculty of Dry Land Agriculture and Natural resource, Department of Cooperatives.

62. Yamane, (1967). Statistics, an introductory analysis, $2^{\text {nd }}$ Ed., New York

63. Zeuli, K., \& Cropp, R. (2004). Cooperatives: Principles and practices in the 21stcentury. wisconsin: Cooperative extension publication, University of Wisconsin extension, Minesota.

APPENDix

\section{Mizan Tepi University}

\section{College Of Business And Economics}

\section{Department Of Cooperatives}

\section{Dear respondent,}

Instructions:

$\checkmark$ Please do not enter your name or contact details on the questionnaire. It remains anonymous.

$\checkmark$ Please indicate your answers with a check mark $(\sqrt{ })$ in the appropriate block for Likert scale type statements and multiple choice questions.

\section{Section 1. General Background of Respondents}

1. Sex

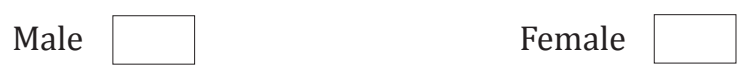

2. Age
18-33
$33-48$
49-63
64 \& over

3. Your highest educational qualification?

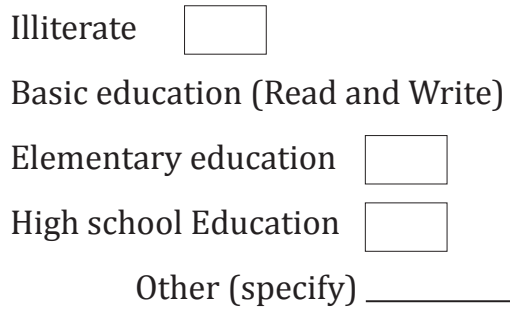

4. Marital status:

Married $\square$ Single $\square$ Divorced $\square$ Widowed $\square$

\section{Section 2. Evaluation of Cooperative Development}

In this section, you evaluate your cooperatives' in achievement trend of "service offerings", and "satisfaction" among the members in consideration of the past performance. And evaluate them in relation to your society and then put a tick mark $(\sqrt{ })$ under the choices below. Where, $1=$ Very low, $2=$ Low, $3=$ Medium $4=$ high and 5 $=$ Very high. 
Challenges on the Development of Cooperatives: The Case of Bench Maji Zone, SNNP Regional State

5. How do you evaluate your society development in terms of increase the "service offering" to the members and enhance the "satisfaction" among the members.

\begin{tabular}{|c|c|c|c|c|c|c|}
\hline S.No. & Level of development & 1 & 2 & 3 & 4 & 5 \\
\hline 1 & Very low & & & & & \\
\hline 2 & Low & & & & & \\
\hline 3 & Medium & & & & & \\
\hline 4 & High & & & & & \\
\hline 5 & Very high & & & & \\
\hline
\end{tabular}

Section 3. Challenges to the Development of Cooperative Organization

The major challenges to the development of Cooperatives organization are listed below.

Please indicate the degree of influence to which these factors are contributed the development of your society. After you read each of the challenging factors, evaluate them in relation to your society and then put a tick mark $(\sqrt{ })$ under the choices below. Where, $1=$ least challenging (very low), $2=$ challenge slightly (low), $3=$ challenge moderately (medium), $4=$ challenge highly (high) and $5=$ challenge critically (very high).

6. Please indicate the degree of challenge of each of the mentioned factors below concerning management factor in your society.

\begin{tabular}{|c|c|c|c|c|c|c|}
\hline S. No. & Managerial factor & 1 & 2 & 3 & 4 & 5 \\
\hline 1 & Interpersonal skills of managers & & & & & \\
\hline 2 & Understanding the concept of cooperative & & & & & \\
\hline 3 & Interest of management to work in cooperatives & & & & & \\
\hline 4 & Educational level & & & & & \\
\hline 5 & General business and managerial skills & & & & & \\
\hline 6 & Efficient conflict solving abilities & & & & & \\
\hline 7 & Good experience of managers in cooperative & & & & & \\
\hline
\end{tabular}

7. Please indicate the degree of challenge of each of the mentioned factors below concerning structural factor in your society.

\begin{tabular}{|c|c|c|c|c|c|c|}
\hline S. No. & Structural factor & 1 & 2 & 3 & 4 & 5 \\
\hline 1 & Member homogeneity & & & & & \\
\hline 2 & Good relationship with other cooperatives & & & & & \\
\hline 3 & Large number of workers & & & & & \\
\hline 4 & Availability of well-structured facilities & & & & \\
\hline 5 & Practice of sharing experiences of other successful cooperatives & & & & & \\
\hline 6 & Members cooperation & & & & & \\
\hline
\end{tabular}

8. Please indicate the degree of challenge of each of the mentioned factors below concerning awareness factor in your society

\begin{tabular}{|c|c|c|c|c|c|c|}
\hline S. No. & awareness factor & 1 & 2 & 3 & 4 & 5 \\
\hline 1 & Member access to timely and worthwhile information & & & & & \\
\hline 2 & Awareness on member owner responsibility and benefits & & & & & \\
\hline 3 & Awareness of related cooperative news and market trends & & & & & \\
\hline 4 & Accuracy of messages cooperatives communicate to members & & & & & \\
\hline 5 & Provide regular feedback to members to allow them to share in collective success & & & & & \\
\hline 6 & Good communication medium & & & & & \\
\hline
\end{tabular}

American Research Journal of Business and Management

Page 17 
Challenges on the Development of Cooperatives: The Case of Bench Maji Zone, SNNP Regional State

9. Please indicate the degree of challenge of each of the mentioned factors below concerning financial factor in your society

\begin{tabular}{|c|c|c|c|c|c|c|}
\hline S. No. & Financial factor & 1 & 2 & 3 & 4 & 5 \\
\hline 1 & Share capital contribution & & & & & \\
\hline 2 & Cash management skill & & & & & \\
\hline 3 & Accessibility of working capital & & & & & \\
\hline 4 & High collateral requirements for Banks and other lending institution & & & & & \\
\hline 5 & Interest charged by Banks and other lending institution & & & & & \\
\hline 6 & Loan application by banks and other lending institutions are complicated & & & & & \\
\hline
\end{tabular}

10. Please indicate the degree of challenge of each of the mentioned factors below concerning politico-legal factor in your society

\begin{tabular}{|c|c|c|c|c|c|c|}
\hline S. No. & $\begin{array}{c}\text { Politico-legal factor } \\
\end{array}$ & 1 & 2 & 3 & 4 & 5 \\
\hline 1 & The tax levied on cooperative business is not reasonable & & & & & \\
\hline 2 & Bureaucracy in cooperative registration and licensing & & & & & \\
\hline 3 & Government support & & & & & \\
\hline 4 & Political intervention & & & & & \\
\hline 5 & Accessible information on government regulation that are relevant to cooperatives & & & & & \\
\hline
\end{tabular}

11. Please indicate the degree of challenge of each of the mentioned factors below concerning entrepreneurial factor in your society

\begin{tabular}{|c|c|c|c|c|c|c|}
\hline S. No. & Entrepreneurial factor & 1 & 2 & 3 & 4 & 5 \\
\hline 1 & Motivation and drive & & & & & \\
\hline 2 & Tolerance to work hard & & & & & \\
\hline 3 & Persistence and courage to take responsibility for one's failure & & & & & \\
\hline 4 & Initiative to assess one's strengths and weakness & & & & & \\
\hline 5 & Accessibility entrepreneurship training & & & & & \\
\hline 6 & Lack of information to exploit business opportunities & & & & & \\
\hline
\end{tabular}

12. Please indicate the degree of challenge of each of the mentioned factors below concerning general factor in your society

\begin{tabular}{|c|c|c|c|c|c|c|}
\hline S. No. & General factor & 1 & 2 & 3 & 4 & 5 \\
\hline 1 & Management factor & & & & & \\
\hline 2 & Structural factor & & & & & \\
\hline 3 & financial factor & & & & & \\
\hline 4 & Awareness factor & & & & & \\
\hline 5 & Politico-legal factor & & & & & \\
\hline 6 & entrepreneurial factor & & & \\
\hline
\end{tabular}

13. What do you suggest to the concerned body to overcome the problem/challenges to the cooperatives development

Citation: Yidenek Woldesenbet. "Challenges on the Development of Cooperatives: The Case of Bench Maji Zone, SNNP Regional State" American Research Journal of Business and Management. 2019; 5(1): 1-18.

Copyright (c) 2019 Yidenek Woldesenbet. This is an open access article distributed under the Creative Commons Attribution License, which permits unrestricted use, distribution, and reproduction in any medium, provided the original work is properly cited. 